\title{
Assessment of Genetic Variability for Yield and Bran oil Content in Segregating Generations of Rice
}

\author{
P. Mahesh Babu*, Y. Chandramohan, V. Ravindrababu and C.H. Arunakumari \\ Department of Genetics and Plant Breeding, Agricultural College, Jagtial, \\ Karimnagar District, Telangana State-505 529, India \\ *Corresponding author
}

\author{
A B S T R A C T
}

\section{Keywords}

Rice segregating generations, Rice bran oil, Variability, GCV, PCV, Heritability, Genetic advance.

Article Info

Accepted:

04 September 2017

Available Online:

10 November 2017
Two hundred progenies of four crosses of rice were evaluated to study the genetic variability in segregating generations for yield and bran oil content. The data was recorded on five randomly selected plants for ten quantitative and four grain quality characters. The analysis of variance showed significant differences for 14 characters studied, indicating the presence of high genetic variability among the progenies. The estimates of GCV were lower than the respective PCV, indicating the influence of environmental factors on the expression of the traits studied. Plant height showed the highest value of heritability and number of filled grains per panicle showed high genetic advance. However, high heritability coupled with low genetic advance was observed for number of productive tillers per plant, panicle length, kernel length, 1000-grain weight and bran oil content indicating that predominance of non-additive gene effects in controlling the character. Hence, the improvement in these characters is not possible through simple selection and requires recurrent selection or heterosis breeding for improvement.

\section{Introduction}

The development of superior rice genotypes involved the intelligent use of available genetic variability both indigenous as well as exotic to cater the need of various farming situations of rice. The grain yield is the primary trait targeted for improvement of rice productivity in both favourable and unfavourable environments from its present level. Knowledge on the genetic architecture of genotypes is necessary to formulate efficient breeding methodology. It is essential to find out the relative magnitude of additive and non-additive genetic variances, heritability and genetic gain with regard to the characters of concern to the breeder. Yield of paddy is controlled by many genes interacting with environment. Selection of parents on the basis of yield is often misleading. Hence, it is imperative to know the cause and effect relationship between yield and yield attributing characters for an efficient selection strategy for the plant breeders. The systematic breeding programme involves the steps like creating genetic variability, practicing selection and utilization of selected progenies to evolve promising genotypes. The large spectrum of genetic variability in segregating populations depends on the level of genetic diversity among genotypes offer better scope for selection. Heritability and genetic advance 
are other important selection parameters. The estimates of heritability help the plant breeder in determining the character for which selection would be rewarding. The breeders are interested in selection of superior progenies based on their phenotypic expression. The major function of heritability estimates is to provide information on transmission of characters from the parents to the progeny.

Heritability estimates can anticipate improvement by selection of useful characters. Heritability estimates along with genetic advance are normally more helpful in predicting the gain under selection than heritability estimates alone. Therefore, estimates of GCV, PCV, heritability and genetic advance will play an important role in exploiting future research projections of rice improvement.

Rice bran is a byproduct of rice processing industry and upon extraction yields rice bran oil. The oil content of rice bran varies in each variety and depends to an even greater extent on the processes and conditions obtained during rice milling. Rice bran, as such, has 15 to $25 \%$ of oil associated with it. It belongs to vitamin E family - a natural antioxidant, which prevents cardio vascular diseases and it is a rich source of gamma - oryzanol (antioxidant) used to treat nerve imbalance and disorders of menopause. It has no cholesterol and no trans-fatty acids and rich in oleic and linoleic fatty acids.

The plant breeders should also focus their attention towards the improvement of rice bran oil content, grain quality and high yield potential. Yield is a complex character determined by a large number of component characters which are considered important in plant breeding. There were no systematic studies on rice bran oil content in improved high yielding varieties in India.

\section{Materials and Methods}

Experimental material consisted of $\mathrm{F}_{3}$ progenies belonging to four $\mathrm{F}_{2}$ crosses selected based on yield superiority, i.e. 40 plants from Keshari x IR-64, 45 plants from Keshari x RPBio226, 60 plants from Keshari $\mathrm{x}$ Swarna and 55 plants from Keshari $\mathrm{x}$ NDR359. A total of 200 progenies were studied in $\mathrm{F}_{3}$ generation during kharif, 2014, at Indian institute of Rice Research (IIRR) Farm, ICRISAT Campus, Patancheru, Hyderabad, Telangana, All the 200 entries belonging to four selected rice crosses were sown separately in a well prepared nursery bed. Twenty seven days old seedlings of each plant were transplanted in two rows of $4.5 \mathrm{~m}$ length by adopting a spacing of $20 \mathrm{~cm}$ between rows and $15 \mathrm{~cm}$ between plants in a randomized block design, replicating twice. All the recommended crop management practices and plant protection measures were followed for raising a healthy nursery and main crop. Observations were recorded on five randomly selected plants from each replication for plant height, number of productive tillers per plant, panicle length, number of filled grains/panicle, total number of grains/panicle, spikelet fertility, kernel length, kernel breadth, L/B ratio and grain yield per plant. However the observations on days to $50 \%$ flowering, days to maturity, 1000- grain weight and bran oil content were recorded on whole plot basis. The data recorded on the above fifteen characters were subjected to the following statistical analysis: Analysis of variance (ANOVA) [1], Variance and Co-efficient of Variance [2, 3], Heritability (Broad sense) [4], and Genetic Advance [5, 6].

For the estimation of bran oil content, rice powder of $0.5 \mathrm{~g}$ was taken into a $50 \mathrm{ml}$ centrifuge tube and $5 \mathrm{ml}$ of $6 \mathrm{~N}$ HCL was added, subjected to vortex, kept in water bath for $1 \mathrm{~h}$ incubation at $80^{\circ} \mathrm{C}$. Then $10 \mathrm{ml}$ of $2: 1$ 
ratio of chloroform: methanol mixture was added, subjected to vertex and kept for incubation in cold room $\left(4^{0} \mathrm{C}\right)$ for overnight. Chloroform layer was transferred into another $50 \mathrm{ml}$ tube which was kept in cold room. Again $10 \mathrm{ml}$ of chloroform: methanol was added to the sample tube, contents were mixed for 3 minutes on a vertex and kept for incubation in cold room $\left(4^{0} \mathrm{C}\right)$ for 4 hours. Again chloroform layer was collected into the second tube, $2 \mathrm{ml}$ of Milli Q water was added, contents were mixed by vortex for 1 minute, and centrifuged at $1500 \mathrm{rpm}$ for 10 minutes. After centrifugation, water layer was discarded, chloroform layer was taken in a glass beaker of known weight (W1) and it was kept in oven maintained at $60^{\circ} \mathrm{C}$ for overnight to evaporate chloroform. After incubation, weight (W2) of the beaker was noted. Simultaneously, moisture percentage was also estimated and values were substituted into the following equation (Bligh and Dyer 1959) [7].

\section{Calculation}

$\begin{array}{cc}\text { W2-W1 } & \text { Total solids }(\mathrm{g} \%) \\ \text { Total oil content }(\text { fat } \%) & =\text { Weight of sample }\end{array}$

Total solids $=100-$ moisture percent

\section{Results and Discussions}

The knowledge of genetic variability present in a given crop species for the character under improvement is of paramount importance for the success of any plant breeding programme. Information on coefficient of variation is useful in measuring the range of variability present in the characters. Heritability and genetic advance are important selection parameters. Genotypic coefficient of variation (GCV) along with heritable estimates would provide a better picture of the amount of genetic advance to be expected by phenotypic selection (Burton, 1952) [5]. It is suggested that genetic gain should be considered in conjunction with heritability estimates (Johnson et al., 1955) [6]. Heritability estimates along with genetic advance are normally more helpful in predicting the gain under selection than heritability estimates alone. The genotypic and phenotypic coefficients of variation, heritability and genetic advance as per cent of mean were estimated for 200 rice progenies.

The analysis of variance revealed highly significant differences among the 200 progenies of rice for all the characters under study indicating considerable genetic variation in the material, the mean sum of squares due to progenies showed significant differences for 14 characters studied among 200 progenies (Table 1), indicating the presence of high genetic variability among the progenies. This would prove to be beneficial for improvement of the crop as reported in rice by Reddy and De [8] and Singh et al., [9].

The significant differences among the progenies studied suggest that variability can be further utilized in crop improvement programme. The estimates of genetic parameters including co-efficient of variation, heritability and genetic advance deserve attention in deciding selection criteria for improvement in the concerned characters.

The estimates of genotypic coefficient of variation (GCV) were lower than the respective phenotypic coefficient of variation (PCV) (Table 2; Fig. 1), indicating the influence of environmental factors on the expression of the traits studied which are in agreement with the findings of Chaubey and Singh [10].

PCV was found to be highest for number of filled grains per panicle (31.32) followed by total number of grains per panicle (22.58), kernel breadth (20.15) and plant height (18.13). 
Table.1 Analysis of variance for 14 characters in $\mathrm{F}_{3}$ generation of rice (Oryza sativa $\mathrm{L}$.)

\begin{tabular}{|c|c|c|c|c|}
\hline \multirow[b]{2}{*}{ S.No. } & \multirow[b]{2}{*}{ Character } & \multicolumn{3}{|c|}{ Mean sum of squares } \\
\hline & & $\begin{array}{c}\text { Replications } \\
\quad(\text { d.f.=1) }\end{array}$ & $\begin{array}{c}\text { Treatments } \\
\text { (d.f.=199) }\end{array}$ & $\begin{array}{c}\text { Error } \\
(\text { d.f.=199) }\end{array}$ \\
\hline 1. & Days to $50 \%$ flowering & 0.09 & $145.80 * *$ & 1.99 \\
\hline 2. & Days to maturity & 2.72 & $100.31 * *$ & 1.72 \\
\hline 3. & Plant height $(\mathrm{cm})$ & 0.11 & $770.96 * *$ & 6.70 \\
\hline 4. & Number of productive tillers per plant & 0.006 & $7.87 * *$ & 0.74 \\
\hline 5. & Panicle length $(\mathrm{cm})$ & 0.009 & $7.63 * *$ & 0.54 \\
\hline 6. & Number of filled grains per panicle & 0.024 & $4253.87 * *$ & 102.19 \\
\hline 7. & Total no of grains per panicle & 0.022 & $3855.40 * *$ & 106.23 \\
\hline 8. & Spikelet fertility \% & 1.30 & $201.14 * *$ & 43.75 \\
\hline 9. & Kernel length (mm) & 0.02 & $1.17 * *$ & 0.04 \\
\hline 10 . & Kernel breadth (mm) & 0.01 & $0.26 * *$ & 0.07 \\
\hline 11. & $\mathrm{~L} / \mathrm{B}$ ratio & 0.10 & $0.40 * *$ & 0.11 \\
\hline 12. & 1000-grain weight $(\mathrm{g})$ & 0.03 & $26.31 * *$ & 0.77 \\
\hline 13. & Grain yield per plant (g) & 0.02 & $65.51 * *$ & 1.39 \\
\hline 14. & Bran oil content $\%$ & 0.01 & $6.34 * *$ & 0.12 \\
\hline
\end{tabular}


Table.2 Magnitude of variability, heritability and genetic advance for 14 characters in $200 \mathrm{~F}_{3}$ progenies of rice (Oryza sativa $\left.\mathrm{L}.\right)$

\begin{tabular}{|c|c|c|c|c|c|c|c|c|}
\hline \multirow{2}{*}{ S.No. } & \multirow{2}{*}{ Character } & \multirow{2}{*}{$\begin{array}{c}\text { General } \\
\text { Mean }\end{array}$} & \multicolumn{2}{|c|}{ Range } & \multirow{2}{*}{$\begin{array}{c}\text { Phenotypic } \\
\text { coefficient } \\
\text { variation } \\
\text { to percent }\end{array}$} & \multirow{2}{*}{$\begin{array}{l}\text { Genotypic } \\
\text { coefficient } \\
\text { variation } \\
\text { to percent }\end{array}$} & \multirow{2}{*}{$\begin{array}{c}\text { Heritability } \\
\text { in broad } \\
\text { sense }\left(\mathbf{h}^{2}{ }_{b s}\right) \\
(\%)\end{array}$} & \multirow{2}{*}{$\begin{array}{c}\text { GA as } \\
\text { per } \\
\text { cent of } \\
\text { mean } \\
\text { (at } 5 \%)\end{array}$} \\
\hline & & & Minimum & Maximum & & & & \\
\hline 1. & Days to $50 \%$ flowering & 95.16 & 76.00 & 115.00 & 9.03 & 8.91 & 97.3 & 17.23 \\
\hline 2. & Plant height $(\mathrm{cm})$ & 108.21 & 62.00 & 151.95 & 18.13 & 17.97 & 98.3 & 39.92 \\
\hline 3. & $\begin{array}{l}\text { Number of productive } \\
\text { tillers/plant }\end{array}$ & 12.62 & 7.90 & 18.20 & 16.44 & 14.95 & 82.6 & 3.53 \\
\hline 4. & Panicle length $(\mathrm{cm})$ & 25.44 & 19.00 & 30.90 & 7.94 & 7.39 & 86.7 & 3.61 \\
\hline 5. & $\begin{array}{l}\text { Number of filled grains / } \\
\text { panicle }\end{array}$ & 146.15 & 64.50 & 220.60 & 31.32 & 30.58 & 95.3 & 91.62 \\
\hline 6. & Total no of grains/panicle & 196.52 & 118.50 & 300.00 & 22.58 & 21.97 & 94.6 & 86.76 \\
\hline 7. & Spikelet fertility (\%) & 74.02 & 48.71 & 92.90 & 14.81 & 11.87 & 64.3 & 14.65 \\
\hline 8. & Kernel length (mm) & 5.77 & 4.00 & 7.14 & 13.54 & 13.01 & 92.3 & 1.48 \\
\hline 9. & Kernel breadth (mm) & 2.04 & 1.50 & 3.12 & 20.15 & 14.72 & 53.4 & 0.45 \\
\hline 10 & L/B Ratio & 2.86 & 1.60 & 5.29 & 17.71 & 13.35 & 56.8 & 0.59 \\
\hline 11 & Days to maturity & 128.94 & 109.00 & 145.00 & 5.54 & 5.44 & 96.6 & 14.21 \\
\hline 12. & 1000-grain weight $(\mathrm{g})$ & 18.78 & 12.55 & 26.85 & 17.73 & 17.21 & 94.3 & 7.14 \\
\hline 13. & Grain yield per plant (g) & 30.67 & 17.16 & 38.92 & 17.78 & 17.40 & 95.8 & 11.41 \\
\hline 14. & Bran oil (\%) & 12.35 & 9.62 & 17.65 & 14.55 & 14.27 & 96.2 & 3.56 \\
\hline
\end{tabular}


Fig.1 Histogram representing the Genotypic Coefficient of Variation(GCV), Phenotypic Ciefficient of Variation (PCV) for fourteen characters in two hundred progenies of rice (Oryza sativa L.)

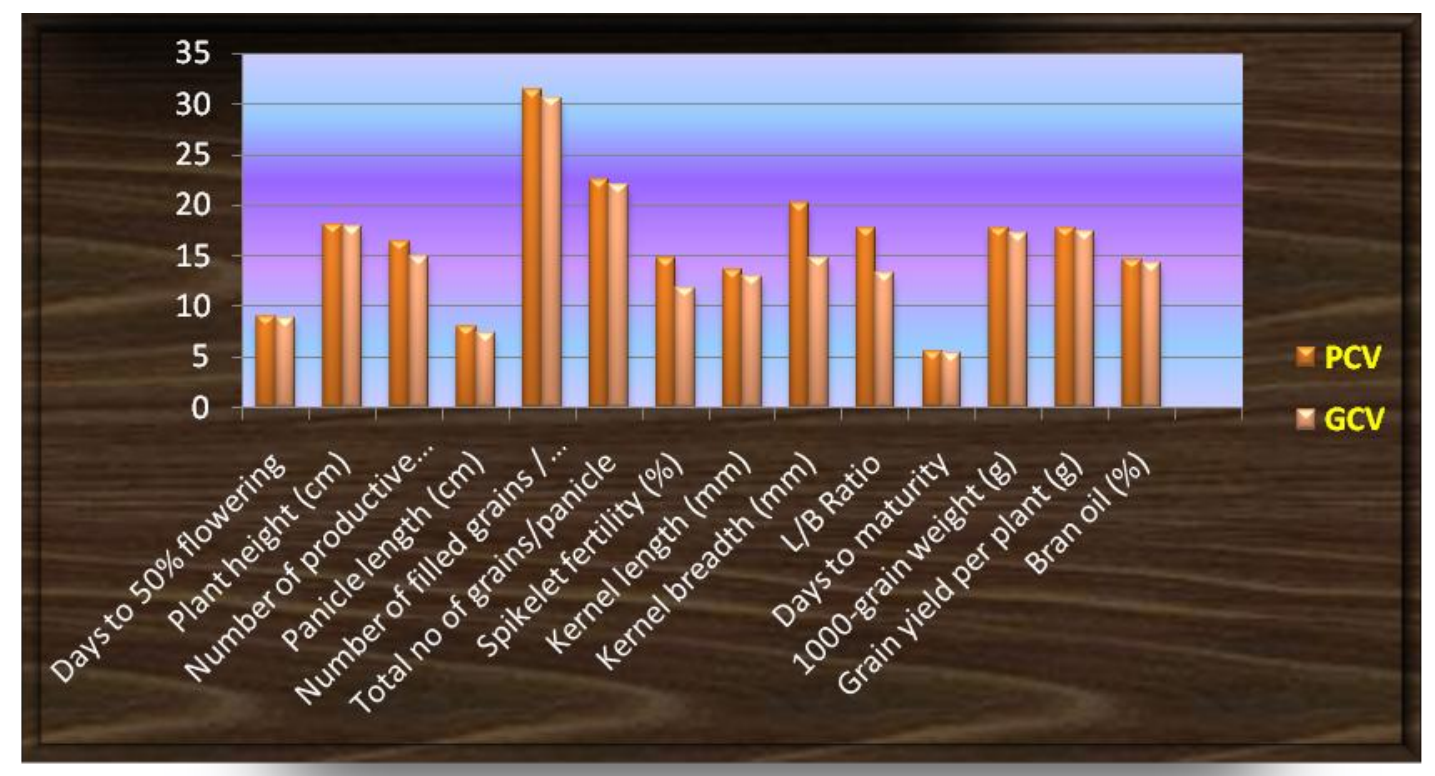

Fig.2 Histogram representing the heritability and genetic advance for fourteen characters in two hundred progenies of rice (Oryza sativa L.)

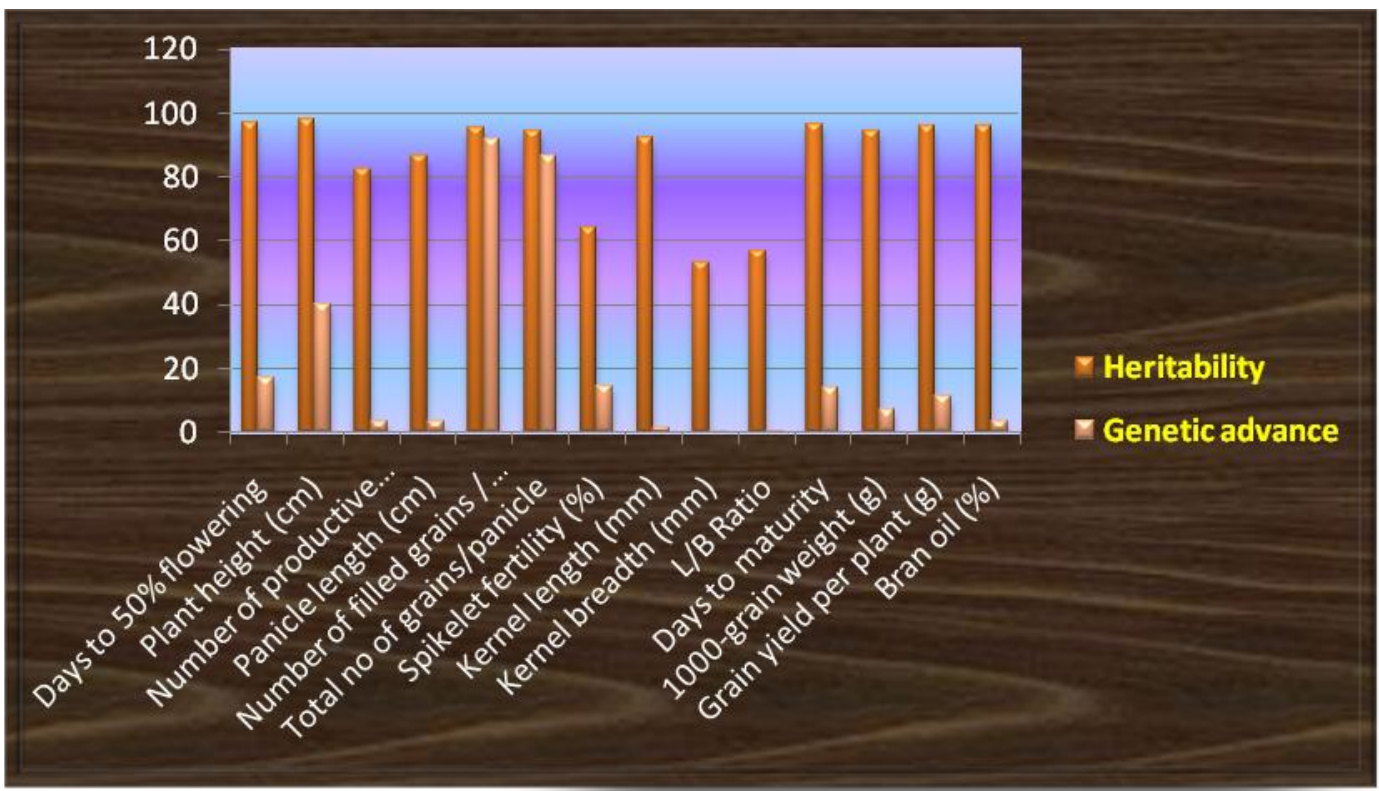


While days to maturity had the least PCV value (5.54) which was significantly differed by panicle length (7.96) and days to $50 \%$ flowering (9.03). Similarly, GCV was found to be highest in number of filled grains per panicle (30.58) followed by total number of grains per panicle (21.97), plant height (17.97) and grain yield per plant (17.40).

But days to maturity had the least GCV value (5.44). Seyoum et al., [11] reported high GCV and PCV for number of filled grains per panicle and Chanbeni et al., [12] reported low GCV, PCV for days to maturity.

Finally, coefficients of variation studies indicated that the estimates of PCV were slightly higher than the corresponding GCV estimates for days to $50 \%$ flowering, days to maturity, plant height, number of productive tillers per plant, panicle length, number of filled grains per panicle, total number of grains per panicle, spikelet fertility, 1000grain weight, grain yield per plant, kernel length, kernel breadth, kernel L/B ratio, bran oil content indicating that the characters were less influenced by the environment. Therefore, selection on the basis of phenotype alone can be effective for the improvement of traits studied.

The estimates of heritability act as predictive instrument in expressing the reliability of phenotypic value. Therefore, high heritability helps in effective selection for a particular character. A perusal of data on heritability (broad sense) (Table 2; Fig. 2) depicted that heritability estimates $(\%)$ for 14 traits under study ranged from $53.4 \%$ to $98.3 \%$. plant height $(98.3 \%)$ showed the highest value of heritability followed by days to $50 \%$ flowering $(97.3 \%)$, days to maturity $(96.6 \%)$, and bran oil content (96.2\%). Least value was observed for kernel breadth (53.4\%) followed by $\mathrm{L} / \mathrm{B}$ ratio (56.8\%). Dhurai et al., [13] reported high heritability for plant height.
A perusal of data on genetic advance as percent of mean (Table 2; Fig. 2) for all the quantitative and qualitative characters under study ranged from $0.45 \%$ (kernel breadth) to $91.62 \%$ (number of filled grains per panicle) Moderate genetic advance was shown by grain yield per plant (11.41\%), days to maturity $(14.21 \%)$, spikelet fertility $(14.65 \%)$ and days to $50 \%$ flowering $(17.23 \%)$. Low genetic advance was observed in kernel breadth $(0.45 \%), \mathrm{L} / \mathrm{B}$ ratio $(0.59 \%)$, kernel length $(1.48 \%)$, number of productive tillers per plant $(3.53 \%)$, bran oil $(3.56 \%)$, panicle length $(3.61 \%)$ and 1000-grain weight (7.14\%). Similarly Ganapati et al., [14] reported high genetic advance for number of filled grains per panicle and Chaudhary et al., [15] reported low genetic advance for kernel breadth.

A moderate genotypic (14.27) and phenotypic (14.55) coefficients of variation and heritability estimate was very high $(96.20 \%)$ with a low genetic advance as per cent of mean (3.56), were observed for the trait bran oil content.

High heritability for quantitative characters indicated the scope of genetic improvement of these characters through simple selection. All grain quality characters studied were also exhibited high degree of broad-sense heritability, which revealed that these characters are less influenced by environment and there could be greater correspondence between phenotypic and breeding values.

The genetic advance as percent of mean is a useful indicator of the progress that could be expected as a result of exercising selection on the pertinent population. High heritability coupled with high genetic advance was observed for plant height, number of filled grains per panicle and total number of grains per panicle indicating that predominance of additive gene effects in controlling the 
character. Hence, the improvement in these characters could be possible through simple selection.

However, high heritability coupled with low genetic advance was observed for number of productive tillers per plant, panicle length, kernel length, 1000-grain weight and bran oil content indicating that predominance of nonadditive gene effects in controlling the character. Hence, the improvement in these characters is not possible through simple selection and requires recurrent selection or heterosis breeding for improvement

\section{References}

Allard, R.W., 1960. Principles of Plant Breeding. John Wiley and Sons publishers. New York USA. 485.

Bligh, E.G., and Dyer, W.J. 1959. A rapid method of total lipid extraction and purification. Canadian Journal of Biochemistry and Physiology. 37: 911-917.

Burton, G.W., 1952. Quantitative inheritance in Grasses. Proceedings of 6th International Grassland Congress. 1: 227-283.

Burton, G.W., and Devane, E.W. 1953. Estimating heritability in tall fescue (Festuca arundiraceae) from replicated clonal material. Agronomy Journal. 45: 478-481.

Chanbeni, Y., Ovung, G. M, Lal and Prashanth kumar Rai. 2012. Studies on genetic diversity in rice (Oryza sativa L.) Journal of Agricultural Technology. 8 (3): 10591065.

Chaubey, P.K., and Singh R. 1994. Genetic variability, correlation and path analysis of yield components of rice. Madras
Agriculture Journal. 81: 468-470.

Chaudhary, M., Sarawgi, A.K and Motiramani, N.K. 2004. Genetic variability of quality, yield and yield attributing traits in aromatic rice. Advances in Plant Sciences. 17 (2): 485-490.

Dhurai, S.Y., Bhati, P.K and Saroj, S.K. 2014. Studies on genetic variability for yield and quality characters in rice (Oryza sativa L) under integrated fertilizer management. An International Quarterly Journal of Life Sciences. 9 (2): 845-848.

Falconer, D.S., 1981. Introduction to quantitative genetics. Oliver Boyd, London pp. 340.

Fischer, R.A., and Yates, F. 1967. Statistical tables for biological, agricultural and medical research. Olive Boyd, Edinburgh.

Ganapati, R.K., Rasul, M.G., Mian, M.A.K and Sarker, U. 2014. Genetic Variability and Character Association of T-Aman Rice (Oryza Sativa L). International Journal of Plant Biology Research. 2 (2): 1013.

Johnson, H.W., Robinson H.F and Comstock R.E. 1955. Genotypic and phenotypic correlations in soyabean and their implications in selections. Agronomy Journal. 47: 477-483.

Reddy, J.N., and De R.N. 1996. Study of genetic variability, heritability and genetic advance for panicle characters in rice. Oryza 35: 1921.

Seyoum, M., Alamerew, S and Bantte, K. 2012. Genetic variability, heritability, correlation coefficient and path analysis for yield and yield related traits in upland rice. Journal of Plant Sciences. 7 (1): 13-22.

Singh, S.P., Singharia G.S., Parry G.A and Bhat G.N. 2005. Genetic variability and heritability in rice (Oryza sativa L.). Environmental Ecology. 3: 549-551.

\section{How to cite this article:}

Mahesh Babu, P., Y. Chandramohan, V. Ravindrababu and Arunakumari, C.H. 2017. Assessment of Genetic Variability for Yield and Bran oil Content in Segregating Generations of Rice. Int.J.Curr.Microbiol.App.Sci. 6(11): 117-124.

doi: https://doi.org/10.20546/ijcmas.2017.611.015 